\title{
POR UMA CARTOGRAFIA DAS POÉTICAS DA VOZ NA BAHIA: MÉTODOS DE REGISTRO E INTERPRETAÇÃO
}

\author{
Edil Silva Costa ${ }^{1}$ \\ Daiane de Araújo França²
}

\begin{abstract}
Resumo: Este artigo está dividido em duas partes: em um primeiro momento trata-se dos estudos sobre literatura oral e do Projeto Cartografia de Poéticas Orais do Brasil. A partir dos estudos das poéticas da voz na Bahia, discute-se a metodologia da pesquisa para a literatura oral, que exige do pesquisador a interação com outras áreas do conhecimento e a adequação do aparato teórico dos estudos literários e culturais. Temos como questão de pesquisa de que modo as comunidades tradicionais mantêm e ressignificam sua cultura na contemporaneidade. Na segunda parte do artigo, exemplificando a metodologia de abordagem das literaturas da voz, com suas especificidades, e retomando a questão de pesquisa, apresenta-se uma manifestação da cultura popular de uma comunidade da região sisaleira da Bahia, o "Boi Roubado".

Palavras-Chave: Literatura oral, M étodo, Tradição, Cartografia, Boi Roubado.
\end{abstract}

Abstract: This article is divided into two parts: in the first it presents the study of oral literature and the Projeto Cartografia de Poéticas Orais do Brasil. Based on studies of the poetic voice in Bahia, it discusses the research methodology for oral literature, which requires the researcher to interact with other areas of knowledge, and the suitableness of the theoretical apparatus of literary and cultural studies. The research project focus on how communities maintain and reframe their traditional culture in contemporary society. The second part of the article, illustrates the methodological approach of the literatures of the voice, with its specificities, resumes the research question, and presents a demonstration of the popular culture of a community of sisal region of Bahia, the "Boi Roubado".

Keywords: Oral literature, M ethod, Tradition, Cartography, Boi Roubado.

1 Professora Titular junto ao Curso de Letras da Universidade do Estado da Bahia (UNEB), Campus II/Alagoinhas; Coordenadora do Programa de Pós-Graduação em Crítica Cultural (Pós-Crítica/UNEB); M embro do GT de Literatura Oral e Popular da ANPOL (Associação Nacional de Pós-Graduação e Pesquisa em Letras e Linguística); Doutora em Comunicação e Semiótica pela Pontifícia Universidade Católica de São Paulo (PUC/SP). Endereço eletrônico: escosta@uneb.br.

2 Mestranda no Programa de Pós-Graduação em Estudos Literários, da Universidade Estadual de Feira de Santana (PROGEL/[ex-PPGLDC]/UEFS). Endereço eletrônico: dainane2006 @ hotmail.com. 


\section{INTRODUÇÃO}

Também me surpreendo, os olhos abertos para o espelho pálido, de que haja tanta coisa em mim além do conhecido, tanta coisa sempre silenciosa (Clarice Lispector, Perto do coração selvagem).

No campo de estudo da teoria literária quase nada se fez considerando as literaturas da voz. A pesquisa em letras historicamente prestigiou 0 texto escrito deixando a análise das produções orais para a linguística ou para a antropologia. Pensar em uma teoria da literatura oral, no entanto, exige o esforço de romper fronteiras do conhecimento, pois não seria possível analisar um texto oral sem levar em conta seu contexto de produção. De modo que seria inviável, ou pelo menos pouco produtiva, a análise do texto pelo texto.

Com o avanço dos estudos comparados e a intensificação do diálogo dos estudos culturais com a área de letras, pode-se ampliar nossos horizontes no sentido de incluir os discursos posto à margem do cânone, como é o caso da literatura oral popular. Porém, as ferramentas logo se mostraram insuficientes, exigindo do pesquisador da área de letras um esforço para adequar os instrumentos de análise, saindo da sua zona de conforto, como deve ser para todo sujeito que se propõe à produção de conhecimento.

Este sempre foi um dos principais embates dos pesquisadores do Grupo de Trabalho de Literatura Oral e Popular da ANPOLL (Associação Nacional de Pós-Graduação e Pesquisa em Letras e Linguística), desde a criação do GT na década de 80. De lá para cá, além de abrir caminhos e consolidar o espaço da Literatura Oral e Popular nos estudos literários e no conservador espaço da academia, os pesquisadores deram atenção à formação de acervos e à produção sistemática de análises dos materiais coletados. 0 resultado desse esforço é documentado nas dissertações e teses defendidas nos últimos trinta anos, muitas delas publicadas parcial ou integralmente em artigos e livros.

Com o objetivo de conhecer o estado da arte das poéticas orais e mapear os pesquisadores e grupos de pesquisa na área, os pesquisadores do GT vêm trabalhando de forma integrada no Projeto Cartografia de Poéticas Orais do Brasil ${ }^{3}$ e aos poucos suprindo as lacunas em relação a teoria e método de estudo das poéticas da voz.

3 Projeto proposto e coordenado pelo prof. Dr. Frederico Augusto Garcia Fernandes (UEL), enquanto coordenador do GT de Literatura Oral e Popular da ANPOLL e teve início em 110 Número temático: M etodologias de pesquisa em ciências sociais e humanas. A Cor das Letras 
Desde os trabalhos pioneiros dos estudos folclóricos no Brasil até hoje, percebemos que muito já se avançou no sentido tanto do aparato teórico quanto da metodologia. Porém, ainda há um longo caminho a se percorrer. Procurando-se distanciar dos folcloristas que privilegiavam o registro (ou "resgate"), alardeando seu temor pela certeza do desaparecimento das tradições, os estudos contemporâneos tendem a privilegiar a interpretação do texto cultural, incluindo as diversas linguagens. Um dos temas com os quais temos nos ocupado, e que envolve também o registro, é o estado atual da tradição oral, suas formas de transmissão e as configurações que recebem na contemporaneidade. Em especial, a partir do estudo e pesquisa da literatura oral, de que modo as comunidades tradicionais mantêm e ressignificam sua cultura.

A abordagem desse tema, como foi dito, vai exigir do pesquisador afinar seus instrumentos e a aproximação das comunidades, com ouvido fino e disponibilidade para a escuta. Isso implica atenção e cuidado com a adequação do aparato teórico dos estudos literários e culturais para encontrar uma metodologia de abordagem das literaturas da voz, com suas especificidades.

\section{VOZES E ESCUTAS NA CONTEM PORANEIDADE}

Conectada a uma tradição e a um grupo humano, a literatura oral cria um mundo e projeta uma imagem desse grupo por onde transita, que por sua vez é construída pelos valores que o texto carrega. Desse modo, seu contexto de produção e suas condições de recepção fazem parte do texto. As narrativas são controladas com o rigor da censura coletiva para garantir a conservação de uma forma preestabelecida e de uma carga simbólica que perpassa o processo de transmissão, estabelecendo uma ponte do passado com o presente. Quando o texto tradicional é apropriado por outras linguagens e veiculado pela cultura de massa, esse rigor de repetir o modelo é enfraquecido, em nome da liberdade de criação e na tentativa de encontrar novas formas de dizer.

$\mathrm{Na}$ comunidade narrativa tradicional, as marcas do passado vão sendo atualizadas na repetição/transmissão do texto que faz a tradição sempre contemporânea. Em uma comunidade tradicional há o imenso prestígio do

2008. O Projeto envolve pesquisadores de todas as regiões do Brasil (UEL, Unicamp, UFBA, UNEB, UFGD, UFMT, CEFET/MT, UFPA, UNEB, Unipampa, UFRGS). 
já-dito e daquele que diz (aquele sujeito que já disse, diz e dirá novamente algo bem-dito e sabido por seus pares).

Ressalva-se que o termo "narrativas" é tomado aqui no sentido amplo, como textos diversos que são falados, cantados, dançados e dramatizados e que constroem assim um sentido para os modos de vida de uma comunidade.

As narrativas, assim como os cantos e demais práticas tradicionais, sofrem ajustes continuamente na cadeia de transmissão, sendo sempre renovadas consonantes com o momento e com os ouvintes/participantes. 0 movimento da tradição, às vezes lento, noutras mais acelerado, é regularizado pelos transmissores em função da qualidade comunicativa do texto e sua funcionalidade. Paul Zumthor (1997) se refere à autoridade da voz viva do narrador e a presença de seu corpo do qual emana o texto, prolongando-o e presentificando-o. Essa presença assegura a permanência de discursos e demarca territórios, mesmo em sociedades tecnicamente avançadas, que deixam à voz um espaço restrito, salvo as mediatizações. Por outro lado, a voz mediatizada amplia seu alcance, o que poderá resultar na ocupação de outros espaços aonde a voz tradicional não se faz presente.

No século XXI, os meios tecnológicos oferecem uma diversidade de suportes novos para as narrativas, sejam elas tradicionais ou não. Pensar a tradição oral na contemporaneidade é incluir esses suportes. A pesquisa em oralidade não pode deixar de observar como as narrativas persistem e encontram novos caminhos. Não obstante as falam que profetizam o fim das narrativas e a destruição das tradições orais por causa do avanço das novas tecnologias, o hábito de narrar permanece assumindo novas formas e suportes. O narrar precisa do coletivo, do estar com o outro, da presença e do contato (ainda que virtual). Assim como os seres humanos. Mesmo na contemporaneidade, em que o tempo é cada vez mais escasso, o estar com 0 outro é essencial e favorece a troca e o narrar, seja uma anedota ou um acontecimento corriqueiro do cotidiano. Essa necessidade de narrar nos aproxima dos nossos ancestrais. Porém, de que modo as narrativas são reorganizadas no contexto atual?

Na medida em que transmite situações e valores, a literatura tradicional reforça vínculos e é, sem dúvida, um modo de os indivíduos se situarem no mundo (ZUMTHOR, 1997, p. 52). Por sua posição à margem, de certa forma se resguarda das rápidas mudanças impostas pela modernidade. Os textos da tradição constituem parte de um lastro que fundamenta a cultura. Daí a importância de registrá-los. Porém, o registro só não basta. 0

112 Número temático: M etodologias de pesquisa em ciências sociais e humanas. A Cor das Letras 
pesquisador caminha na busca de sentidos para as narrativas. Mas como enfrentar esses textos? Não é possível descolar a leitura da experiência de campo, do contato com os narradores, da memória da performance.

Para se pensar em uma poética da voz na contemporaneidade devese incluir a oralidade mediatizada por esses suportes, para além da presença física de um narrador e de uma situação de transmissão idealizada, à sombra de uma árvore ou em volta de uma fogueira.

Uma metodologia de estudo das narrativas tradicionais deverá contemplar esse emaranhado complexo, se consideramos desde a recolha até a adaptação e publicação dos textos. Tendo como uma de suas linhas de ação o registro da literatura oral no Estado, é isso que tem mostrado a experiência metodológica desenvolvida com as ações do Projeto Acervo de Memória e Tradições Orais na Bahia: cartografias ${ }^{4}$ e que por sua vez filia-se a uma tradição de estudos das poéticas da voz no Brasil, iniciado com os estudos folclóricos no século XIX, mas que se consolidou no século XX, ganhando corpo e novas perspectivas a partir da década de 80.

\section{PROJETO CARTOGRAFIAS: PESQUISADORES E SEUS EMBATES}

A proposta de cartografar as poéticas orais parte da necessidade de se conhecer o caminho já trilhado e qual o estado da arte desses estudos hoje, e é objetivo dos grupos de pesquisa filiados à mais importante associação de pesquisadores na área de Letras, a ANPOLL. Como já foi dito, o Grupo de Trabalho Literatura Oral e Popular reúne pesquisadores de vários Estados e regiões do Brasil que procuram discutir e socializar suas pesquisas para seguir uma linha de trabalho não uniforme, mas com objetivos comuns e coerentes com as peculiaridades de cada região.

Os resultados dessas pesquisas e as questões pertinentes às pesquisas do grupo vêm sendo tema do Seminário Brasileiro de Poéticas Orais, já em sua terceira edição em 2013 e dos encontros nacionais do GT de Literatura Oral e Popular já mencionado, no âmbito da ANPOLL. Contamos hoje com significativa quantidade de publicações sobre o tema e muitas pesqui-

4 O Acervo de Memória e Tradições Orais na Bahia (AMTRO), desenvolvido no âmbito da Universidade do Estado da Bahia, começou a ser constituído 1995 e é composto de textos orais e impressos, fotos, vídeos e obras artísticas, registros da cultura popular dos municípios de Alagoinhas, Inhambupe, Mata de São João, Catu, Pojuca, Teodoro Sampaio, Irará e Camaçari. 
sas em andamento, abrangendo desde o nível da iniciação científica ao doutorado.

É deste lugar de fala que propomos pensar a metodologia para a pesquisa das literaturas da voz. Neste primeiro momento, os exemplos citados relacionam-se à coleta de contos populares, pois tem sido este, no vasto universo das tradições orais, o tipo de texto mais registrado entre as narrativas que compõem o Acervo.

0 trabalho de campo é um passo importante para o estudo das tradições orais. Não se quer dizer com isso que, para se pensar a poética da voz, não se possa partir de textos já estabelecidos. Há no Brasil, desde Silvio Romero e Câmara Cascudo, coletâneas de contos populares que documentam os contos tradicionais e que oferecem um farto material de pesquisa. Porém, o trabalho de campo permite o contato direto com as fontes, a recolha de amostras, a vivência com o narrador em performance e seu cenário. A experiência com o texto em seu momento e contexto de produção não é algo que o aprendizado teórico possa contemplar.

Já sabemos que a pesquisa de campo para a literatura e a linguagem oral não é abordada nos manuais de teoria na área de Letras. Por essa razão, em geral, os pesquisadores que se inclinam para este tipo de estudo têm que buscar suporte em outras áreas do conhecimento. No campo mais específico dos estudos da linguagem, o método de trabalho da sociolinguística é o que mais se aproxima do nosso tipo de pesquisa, envolvendo entrevistas, transcrição e análise dos dados, visando o estabelecimento de um corpus. Nesse momento, o método de entrevista da História Oral é bastante promissor para a preparação da pesquisa e tem apontado caminhos para 0 pesquisador na área da literatura oral.

Para os estudiosos da literatura que costumam cultuar os poetas mortos, lidar com a poesia enquanto palavra oral, a voz viva como diz Zumthor, é, no mínimo, incômodo. A principal diferença no enfrentamento de nossos "objetos de estudo" é que não lidamos com objetos, mas com sujeitos. Não se quer aqui comparar as riquezas da pesquisa em bibliotecas com as da pesquisa de campo. Mas sem dúvida que a pesquisa de campo exige um contato humano que pode ser minimizado na pesquisa bibliográfica que é, na maior parte dos casos, individual. A pesquisa de campo exige do pesquisador a interação e um mínimo de integração com a comunidade pesquisada. No contato com os sujeitos portadores do saber popular e dos textos da literatura oral, onde está o índice? Onde as referências bibliográ- 
ficas? Como vou saber o que ele sabe, o que leu e assimilou, se eu não perguntar? Por outro lado, como poderia perguntar sem saber ouvir?

Claro que não há uma metodologia pronta e aplicável quando lidamos com pessoas. Na vida acadêmica, nos acostumamos a projetar e executar planos de trabalho. Mas ao sair desse ambiente, temos que resolver com improvisos as surpresas dos encontros. Em campo, somos sempre invasores, ainda que estejamos em um ambiente familiar para nós e entrevistando velhos conhecidos. A condição de pesquisador é sempre uma intromissão na vida particular dos sujeitos que vão construir uma narrativa de si e de seu grupo humano de acordo com a relação que se estabelecer com 0 intruso. A pesquisa sistemática exige o estudo prévio de cada região, com informações gerais a respeito da comunidade a ser visitada, facilitando 0 trabalho prático.

Devido à ausência de um método pronto que pudesse ser aplicado à recolha da literatura oral, a metodologia da pesquisa vai sendo construída a partir da experiência, sendo a primeira etapa a localização dos narradores. As informações prévias a respeito da região em foco incluem as indicações de possíveis narradores. A aproximação com os narradores pode não ser a parte mais fácil do processo, mas certamente é uma das mais gratificantes, pois frequentemente resulta no estabelecimento de laços amigáveis entre as partes envolvidas. 0 texto tradicional é um bem comum, mas que se manifesta no ambiente familiar, íntimo e tranquilo. Para uma boa performance, é preciso criar um espaço semelhante, apesar da presença do pesquisador - um intruso ao grupo e, a princípio, estranho a sua cultura -e do gravador, máquina fotográfica e demais materiais de trabalho. A habilidade do pesquisador consiste em se inserir no ambiente da pesquisa, romper as barreiras de resistência, diminuindo a distância entre ele e o narrador.

M uitas vezes a ansiedade leva a indagação de um texto de interesse específico para o pesquisador no início da sessão, o que pode não ser 0 melhor. A paciência de esperar pelo acionamento da memória, o "esquentamento" do narrador é quase sempre recompensada com a colheita de textos mais claros e bem elaborados. É preciso deixar o narrador livre, à medida do possível, para que ele escolha o que quer dizer, pois deixar o repertório a critério do entrevistado pode revelar quais os textos da preferência do narrador e que estão mais presentes, lembrando que ele é um representante da memória coletiva e do gosto popular. Mas quem é este sujeito? 
0 estudo do perfil dos narradores do Acervo revela que a grande maioria é do sexo feminino, possui entre trinta e sessenta anos. Quanto à escolaridade, a maior parte dos entrevistados é de não escolarizados, analfabetos ou semianalfabetos. Em seguida, os que não completaram o curso primário. Disso se conclui que o perfil do narrador dos contos orais é o de uma mulher, entre os trinta e um e sessenta anos e não escolarizada.

As narradoras são maioria, principalmente, em se tratando de contos de encantamento. Os homens são melhores narradores de fafécias e de exemplos, com brilhantes exceções, felizmente. As atividades femininas, mais voltadas para o interior da casa e da família, certamente contribuem para o fato, embora se tenha observado que, na presença do homem, a mulher costuma se calar. 0 domínio e o exercício da palavra é, sem dúvida, uma expressão de poder que, numa sociedade patriarcal, é privilégio masculino, com exceção do ambiente familiar, espaço para a educação dos fiIhos, tarefa eminentemente das mulheres. Aí a palavra feminina tem seu espaço também e é principalmente ela 0 instrumento de transmissão da literatura oral. Quando, na Idade Média, o exercício da palavra era uma atividade prestigiosa, pública e profissional, eram os homens que pronunciavam a voz poética, com muito mais rara participação feminina, uma vez que as jogralesas exerciam o papel principalmente de dançarinas.

0 narrador é um instrumento. Ele empresta sua voz e seu corpo inteiro para veicular a memória coletiva, generosamente. A exemplo dos jograis da Idade M édia e dos griôs das comunidades tradicionais africanas, os narradores são intérpretes, mas também criadores. Sua criação é edificada sobre a voz e a presença física do artista. Por essa razão não se deve falar em anonimato relacionado aos textos da tradição oral, pois a autoria, que pode ficar diluída na crença da criação coletiva, é uma marca que fica "impressa" em cada versão, única, do texto realizado. Os valores transmitidos pelo texto estão de acordo com esse perfil e com a condição social desse sujeito.

Para garantir sua conservação e facilitar a análise posterior, os textos gravados precisam ser transcritos e digitalizados. Toda a performance jamais poderá ser apreendida pelo gravador, câmara de vídeo e muito menos numa folha de papel. A transcrição do texto oral inevitavelmente irá reduzilo porque nela se perde a presença do ator e o movimento que ele garante ao texto. A linguagem usada pela maioria dos narradores, como já disse, iletrados, está longe da língua padrão e a transcrição deve respeitar essa expressão linguística. Registrando formas que correspondam à realização, 
tanto a nível fonético, como morfo-sintático e lexical, o pesquisador estará evitando a discriminação do dialeto do informante. Além do mais, muitas vezes, o desvio da forma padrão tem sua função estética, não se tratando exatamente da ignorância da norma, mas da criação de novas expressões que explodem em significados.

As onomatopeias são possivelmente as expressões mais difíceis de transcrever e que traduzem a criatividade do narrador e a sua familiaridade com sons da língua e dos que estão fora dela. São expressões que traduzem subjetivamente o que cada som suscita no indivíduo. A combinação de sons diversos, a princípio sem significados, expressa o que nenhuma palavra da língua poderia expressar porque restaura o gesto e a ação no seu momento acontecido. 0 que a transcrição de um texto oral não pode perder de vista é a presença daquele que narra.

É preciso também ouvir os silêncios, tão eloquentes e surpreendentes quanto as palavras. E muito difíceis de se registar.

Feita a transcrição, o texto não só está mais próximo do pesquisador como passa a fazer parte dele também, a espelhá-lo. A memória do momento da performance e da fruição do texto - do qual o pesquisador foi ouvinte e será também um narrador em potencial - 0 acompanha em sua análise. Será isso um problema? Pode-se pensar que sim como também se pode tomar como vantajosa essa condição de pesquisador-objeto, na medida em que a leitura do texto passará pela ressonância que ele terá em nós e em nossa cultura.

Outra questão que não pode ser ignorada pelo pesquisador é a complexidade dos textos da poesia popular que, como se disse, envolve linguagem verbal, corporal e prática social, de modo que não prescinde da presença dos sujeitos. Um texto oral só existe em performance. É a observação atenta do conjunto de performances, assim como a escuta sensível dos textos que permitirá ao pesquisador compreender os sentidos que o texto carrega.

Para exemplificar os embates de uma pesquisadora que visa o registro e a análise de uma manifestação poética tradicional e comunitária, apresentaremos a seguir o relato de uma experiência de campo que é parte da pesquisa de Mestrado de Daiane França, no Programa de Pós-Graduação em Estudos Literários da UEFS, em andamento. Trata-se do "Boi Roubado", uma manifestação coletiva lúdica e de trabalho que envolve fortes aspectos cênico-teatrais, performáticos e culturais da região sisaleira na Bahia. 0 estudo dessa prática, e dos cantos de trabalho a ela relacionados, poderá 
revelar a poética do texto oral, assim como as formas de solidariedade e organização social da comunidade pesquisada.

\section{BOI ROUBADO E OS CANTOS DE TRABALHO 5}

Antes de descrever a expressão cultural popular "boi roubado", cabe uma ressalva: aqui se exige a sensibilidade de quem o descreve; exige conhecimento e experiência do pesquisador para não incidir no preconceito etnocêntrico de falar do outro através da própria observação. A experiência de quem vive e/ ou conhece a expressão cultural "boi roubado", assim como qualquer outra manifestação cultural, permite descrever com mais conveniência aquilo que se viu, que se fez, que se apreendeu. Por este motivo, a descrição que segue está vinculada à experimentação, às vivências de quem materializou suas estirpes culturais no seio das comunidades sisaleiras.

Segundo os participantes e conhecedores, o "boi roubado" é uma forma de diversão e trabalho coletivo, visto que um grupo de amigos da comunidade, ao perceberem que o outro necessita capinar uma plantação ou fazer qualquer outro serviço em sua propriedade (plantar feijão, milho, mandioca, sisal etc.; fazer cercas, por exemplo) e não tem condição para realizar tal serviço, dirigem-se, às vezes de maneira secreta, à roça do amigo. Sua denominação pode advir justamente dessa visita secreta a uma fazenda. Importante ressaltar que todos os amigos já combinaram a festa antecipadamente, sem o beneficiado saber. Tudo se inicia pela madrugada quando o proprietário é surpreendido pelos fogos e/ ou tiros de espingarda em sua roça, e este cuida em matar boi, porcos, galinhas ou carneiros para alimentar os amigos/ participantes da farra. A partir desse momento, começa a cantoria com canções na forma de parelha (duplas de cantadores), baseada nos improvisos ou em músicas típicas da localidade. Após o amanhecer, inicia-se o trabalho, seguido também pelas cantorias. Enquanto os homens trabalham no campo, as mulheres fazem as comidas (café da manhã, almoço e janta) e os preparativos para a comemoração no final do dia, em que cantam juntos a bandeira - ritual que envolve duas bandeiras (uma vermelha e outra branca), litros de cachaça, copos, pratos dentre outros objetos, e toadas que louvam aos trabalhadores, ao dono da casa e principalmente à cultura. Depois dessa homenagem, os lavradores fazem um

\footnotetext{
5 Este trecho do artigo foi escrito pela mestranda Daiane França, a partir de sua vivência e experiência de campo.

118 Número temático: Metodologias de pesquisa em ciências sociais e humanas. A Cor das Letras - UEFS, n. 14, 2013
} 
samba (roda de sambadores divididos em parelha que entoam canções e são respondidos por um coro de mulheres que batem palmas e sambam ao som do cavaquinho e do pandeiro até a madrugada) para finalizar a festa.

Nesta manifestação coletiva, estão presentes laços de solidariedade, de auxílio gratuito dos vizinhos e trabalhadores rurais. Este ato não é particular desta expressão cultural do universo rural, mas também das "batas de feijão", "despalha de milho", "boi de roça", "raspa da mandioca", "bumba meu boi", dentre outras. Vale ressaltar que estes aspectos não são particulares da região sisaleira nem somente da cultura brasileira, pois chineses, polinésios e africanos praticam atos de cooperação no esforço comum a um companheiro ou vizinho necessitado para a colheita, salga de carnes, fenação, construção de moradias e aguadas etc. Um aspecto proeminente é a presença de instrumentos musicais, linguagens e expressões artísticoculturais nessas atividades, o que caracteriza a relação do indivíduo com 0 trabalho e com suas celebrações estéticas, ao permitir um ato cooperativo e ao mesmo tempo lúdico para os participantes.

Em trabalho, intitulado Boi roubado: a articulação dos recursos linguísticos performáticos em uma tradição do trabalho em festa (FRANÇA, 2012), fez-se uso dos cantos de trabalho que fazem parte dessa expressão. No referido estudo, objetivou-se conhecer as atividades socioculturais desta região, especificamente por meio da análise dos recursos linguísticos performáticos (códigos especiais, linguagem figurada, paralelismos, traços paralinguísticos, formas especiais, apelo à tradição e negação à performance) em suas manifestações estéticas sociais nos cantos de trabalho. Propôsse em analisar estes aspectos com base nos pressupostos teóricos da Sociolinguística qualitativa aliados aos conceitos de performance e arte verbal desenvolvidos por Zumthor (1993) e Genette (2001 apud FARIAS JÚNIOR, 2004). Partes dos dados para análise foram extraídas de contextos e práticas sociais adquiridos por meio de entrevistas, pesquisas, gravações e a observação do evento.

Dessa forma, todas as informações trabalhadas contribuem para 0 conhecimento da performance como um processo de significação que se relaciona à linguagem, à codificação (o gesto, a entonação) e à enunciação (tempo, espaço, cenário), visto que durante o evento artístico "boi roubado", o grupo comunica suas mensagens tanto verbalmente quanto pelo gesto, pela expressividade corporal, pela musicalidade e pela cenografia, reconhecidos por sua audiência. 0 resultado deste estudo implica na divul- 
gação da memória, da expressão oral e dos rituais articuladores de uma ideologia que fortalece a tradição e a identidade cultural da região sisaleira.

Os cantos de trabalho são cantigas com expressões musicais simples, constituídas por elementos linguísticos que estimulam e reforçam esta prática, que acompanham o trabalho, coordenando os movimentos do corpo. Segundo Renata Conceição dos Santos (em trabalho intitulado Cantos de trabalho: rupturas e permanências no Recôncavo Sul da Bahia. UNEB/Campus V), essas cantigas

\begin{abstract}
[...] dimensionam a consciência do trabalhador sobre o seu papel de sujeito histórico, porque enquanto "versa, brinca e vadia" expõe claramente o entendimento acerca do contexto que o circunda. As canções amenizam a dureza do trabalho, mas acima de tudo são um desafio: é quando suas vozes se utilizam de melodias para questionar a situação a qual são submetidos, para exigir a execução de seus direitos e para de alguma forma transgredirem a ordem. As cantigas possuem esses múltiplos significados: amenizam a dureza do trabalho ritmando o corpo do homem, expõem sentimentos e valores desses trabalhadores, constituindo-se em importantes expressões culturais [...], descortinam possibilidades de sobrevivência desses indivíduos. [...] As cantigas são criações autênticas dos trabalhadores cuja oralidade permite apreender diversos espaços e temporalidades do campo, denotando permanências como a noção de coletividade e as rupturas engendradas cotidianamente, em que a partir de elementos lúdicos conseguem "desafiar" a ordem, uma vez que transformam o trabalho em seu instrumento de divertimento e resistência.
\end{abstract}

Percebe-se que os cantos de trabalho são eficazes para a cultura dos trabalhadores rurais, visto que são capazes de sinalizar ainda os aspectos econômicos e sociais desses sujeitos históricos. Desse modo, estão sempre relacionadas a determinados ofícios e lutas diárias, sendo construções coletivas que revelam muito acerca de uma região e seus saberes. Além disso, constituem-se ainda como admiráveis fontes históricas ao descortinar aspectos culturais, econômicos e políticos de um determinado meio social, já que estas traduzem o espaço e o momento em que foram criadas, assim como a vivência, as dificuldades e as lutas cotidianas dos trabalhadores. Esses aspectos ficam explícitos no seguinte verso:

Acorda vaqueiro, acorda (bis)

Que é hora de trabalhar

A vaca pra tirar leite

0 bezerro quer mamar.

Vaqueiro que não abóia ô aiá

Não quer pegar no berrante ê ê ê ê ê boi... (bis)

120 Número temático: Metodologias de pesquisa em ciências sociais e humanas. A Cor das Letras 
Como ilustra a estrofe acima, as cantigas analisadas relacionam-se, em geral, ao trabalho do homem nordestino, do vaqueiro, do meio rural, principalmente à limpa da terra para o plantio e à limpa do sisal, rememorando práticas como a do "boi roubado", também conhecido em outras regiões do Brasil como mutirão, batalhão ou adjutórios, ratificando a importância dessa prática para o desenvolvimento da economia baiana.

Segundo Renata Santos, que estudou o "boi-de-cova" - prática semelhante ao boi roubado, no Recôncavo Sul da Bahia - , foi observado que no Recôncavo Sul da Bahia no século XIX, quando os lavradores mais pobres precisavam da ajuda para transferir as mudas de fumo, estes convidavam os vizinhos para um dia de trabalho seguido por uma festa, na qual se assava um boi, carneiro, porco, galinha para alimentar os participantes. SemeIhante a este fato, em Beira de Cerca e Macaco - comunidades afro descendentes do município de Candeal -, esta prática de plantar e colher 0 fumo esteve presente em seu período inicial de formação. Em outras comunidades sisaleiras, a exemplo da Fazenda Quixabeira situada no município de São Domingos, esses mutirões são realizados para capinar os pastos e as roças de plantações, limpar o sisal ou plantar milho e feijão.

Nessa perspectiva, enfocar as cantigas de trabalho significa evidenciar um costume existente no universo do homem do campo, em que a ajuda mútua funciona como um dos principais elementos constituintes da interação entre amigos e lavradores. Entretanto, deve-se ter o cuidado para não limitar os significados dessas práticas a uma realidade extinta, nem tampouco distinguir "o viver do lutar, o feminino do masculino, a festa do trabalho, a realidade da política, a linguagem das experiências" (SANTANA, 1998) ou ainda folclorizar os elementos que representam a experiência do homem do campo.

Segundo Thompson (1998), "a cultura popular é rebelde, mas o é em defesa dos costumes", e assim sendo, essas cantigas simbolizam ainda 0 grito e a luta por uma continuidade, por uma permanência da tradição local que sobreviveu até o momento e configura as histórias de vida do povo nordestino através da tradição oral. Isso porque a tradição, assim como a cultura, constitui-se na dinamicidade e como tal, renova e altera-se.

A partir da memória oral, pode-se apreender a tradição e os elementos da vida cotidiana por meio dos depoimentos e significados que os trabaIhadores atribuem às suas vivências. Pode-se ainda descobrir os significados das experiências que construíram um passado e que no presente pode ser relembrada e verbalizada. 
As cantigas de trabalho colhidas com informantes mais velhos ratificam as práticas sociais antepassadas e a religiosidade, além de refletirem determinado contexto social, encontram-se associadas às "lembranças do bom tempo". Esta última afirmação fica explícita nos gestos, no tom de voz e no tom pilhérico dos informantes e, neste trecho, na palavra saudade:

Cachaça e muié bonita

Êta vida de morão

Cachaça e muié bonita

é a minha perdição

Namorar menina nova

Ainda que de São João

Ê saudade ê, ô boi ô ô.

Assim, recordar os cantos de trabalho na perspectiva de integração entre festa e trabalho, expõe o significado do próprio homem do campo acerca de sua cultura: 0 trabalho, no momento em que eles se reúnem prontamente para ajudar o outro, transcorre num tom de brincadeira frente ao labor diário, e, dessa forma, seu meio de sobrevivência torna-se símbolo de luta e prazer.

Ao transcrever as cantigas para o papel perde-se muitas informações tais como a espontaneidade do ritual, o ritmo da cantiga embalando os instrumentos de trabalho (enxada, foice, pá, facão etc.) e o corpo do homem durante 0 trabalho, a presença da pilhéria e ainda a sintonia entre os participantes da parelha. Alguns trechos e 0 apelo de alguns informantes no momento da observação demonstram que as práticas de sociabilidade sofrem intensas modificações, além do apagamento natural e parcial dos próprios cantos.

\section{POR ORA, UMA CONCLUSÃO}

Como esclarecem os exemplos trazidos, a poética da voz encontra na mobilidade, na capacidade de mover-se, transformar-se e adequar-se ao novo, a potência para revitalizar-se. Revelando assim os valores e modos de vida de um grupo e de uma época e a rejeição desses valores e a assimilação de outros ao longo do tempo.

A teoria literária lida com o texto fixado e, embora as leituras que se faça dele não sejam fixas, de todo modo não dá conta destas questões. 0 objeto da teoria da literatura oral é movente como são moventes as leituras e as recriações do texto oral e assim só funciona se conectada a uma teoria 
da cultura e da comunicação, pois abarca diversas linguagens. A dinâmica da cultura é também a da produção do texto. 0 pesquisador deverá aceitar que toda análise será sempre parcial e que um texto nunca terminará de dizer o que tem para dizer.

As cartografias apontam para uma tendência dos estudos das poéticas orais transitando entre a antropologia, a história oral e os estudos culturais. A metodologia proposta, embora não seja fechada, reafirma que 0 texto está impregnado de seu contexto e seus sentidos conectados com as práticas sociais. Desse modo, as comunidades tradicionais mantêm e ressignificam sua cultura na contemporaneidade, em parte por sua funcionalidade e prática de sobrevivência material, em parte pela necessidade de repetir e reafirmar suas identidades com as referências ao passado, ou seja, de sobrevivência da tradição.

Como vimos, documentar e compreender as literaturas da voz exige do pesquisador uma postura firme e sensível, que Ihe permita lidar com suas subjetividades e dos seus sujeitos de pesquisa. E mais: desenvoltura para utilizar instrumentos complexos e sofisticados para o enfrentamento dos desafios da sociedade contemporânea, de tempo acelerado e múltiplos espaços em sincronia, incluindo auscultar o frágil coração selvagem das comunidades tradicionais.

\section{REFERÊNCIAS}

CASCUDO, Luis da Câmara. Literatura oral no Brasil. 3. ed. Belo Horizonte: Itatiaia; São Paulo: Ed. USP, 1984.

CASCUDO, Luis da Câmara. Contos tradicionais do Brasil. São Paulo: Global, 2004.

COSTA, Edil Silva. Cinderela nos entrelaces da tradição. Salvador: Secretaria de Cultura; EGBA, 1998.

FARIAS JÚNIOR, Jorge França de. Um estudo sobre arte verbal: da performance do Cordel do Fogo Encantado ao ethos da cultura popular do sertão do Moxotó em Pernambuco. Revista dos Cursos de Pós-Graduação. Campinas: Unicamp, v. 10, p. 149-63, 18 fev. 2004.

FRANÇA, Daiane de Araújo. Boi roubado: a articulação dos recursos linguísticos performáticos em uma tradição do trabalho em festa. M onografia da Graduação em Letras com Habilitação em Língua Portuguesa e Literaturas. Conceição do Coité: UNEB, 2012.

JAKOBSON, Roman. Le folklore, forme spécifique de création. In: Id. Questions de poétique. Paris: Seuil, 1973.

NASCIMENTO, Bráulio do. Catálogo do conto popular brasileiro. Rio de Janeiro: Tempo Brasileiro; IBECC; Unesco, 2005.

ROM ERO, Silvio. Folclore brasileiro: contos populares do Brasil. Belo Horizonte: Itatiaia; São Paulo: Edusp, 1985. 
SANTANA, Charles d'Almeida. Fartura e ventura camponesas: trabalho, cotidiano e migrações: Bahia 1950-1980. São Paulo: Annablume, 1998.

SANTANA, Charles d'Almeida. Trabalhadores rurais do Recôncavo Baiano: memórias e linguagens. Projeto História: Revista PUC, n. 16. EDUC. 1998.

SANTOS, Renata Conceição dos. Cantos de trabalho: rupturas e permanências no Recôncavo Sul da Bahia. In: ANAIS do III Encontro Estadual de História: poder, cultura e diversidade - ST 11: poder, culturas, conflitos e violência no campo brasileiro. Disponível em: http://www.uesb.br/anpuhba/artigos/anpuh_II//renata_conceicao.pdf. Acesso em: 28 mar.. 2011.

THOM PSON, Edward P. Costumes em comum: estudos sobre a cultura popular tradicional. São Paulo: Cia. das Letras, 1998.

ZUM THOR, Paul. A letra e a voz: a "literatura" medieval. São Paulo: Cia. das Letras, 1993.

ZUM THOR, Paul. Introdução à poesia oral. São Paulo: Hucitec, 1997.

ZUM THOR, Paul. Performance, recepção e leitura. São Paulo: Educ, 2000. 


\title{
MÍDIA AUTÓCTONE E INCLUSIVA EM PERIFERIAS URBANASE [SUB]URBANAS: ALGUM AS CONSIDERAÇÕES ACERCA DE PESQUISAS EM COMUNICAÇÃO COMUNITÁRIA
}

\author{
Ricardo Olivaira de Freitas ${ }^{1}$
}

Resumo: Considerando o fenômeno de visibilização de iniciativas de comunicação popular e comunitária, o texto ora apresentado aborda os métodos e as técnicas utilizadas na pesquisa acerca dos processos de comunicação e das interações sociais destes resultantes, a partir do lugar ocupado pelas mídias audiovisuais (vídeo, TV comunitária e cinema de rua) para o desempenho das identidades minoritárias e suas expressões no Brasil. Para tanto, analisa a reincidência de produções que tomam o debate sobre o minoritário e periférico como tema central, constituindo o campo das mídias radicais alternativas, com base nos novos movimentos e nas ações que têm encontrado na mídia (grande mídia e mídias radicais alternativas) importante suporte para desenvolvimento de novas expressões e alianças político-sociais entre democracia, terceiro setor, sociedade civil e grupos ideologicamente minoritários - elaborando, assim, novos modos de representação contra-hegemônicos, com a promoção de políticas públicas e/ou culturais para a inclusão social. Investiga, portanto, a apropriação e utilização de recursos de mídia audiovisuais por grupos e comunidades ideologicamente minoritários, no almejo de alcançarem reconhecimento junto à esfera de visibilidade pública e, por extensão, à esfera pública política, a partir da análise e da elaboração de uma cartografia das iniciativas de comunicação popular e comunitária desenvolvidas na periferia de Salvador.

Palavras-Chave: Cultura de minorias, Representações, Mídias alternativas, Comunicação e movimentos sociais, Comunicação popular.

Abstract: This paper aims to analyze processes of communication and social interactions as a result of the emergency of popular and communitarian communication. It analyzes also the recurrence of productions that refers to the debate about minorities as central subject, constituting the field of the radical alternative media. It investigates therefore the appropriation and use of the technologies of media by minority communities which try to achieve recognition by the sphere of public visibility and, therefore, the political public sphere, based on the analysis and the development of a cartography of popular and communitarian communication initiatives developed on the poor areas of Salvador.

Keywords: Minorities culture, Representations, Alternative media, Communication and social movements, Popular communication.

1 Professor Titular da Universidade do Estado da Bahia (UNEB), Campus I, Salvador; Docente do Programa de Pós-Graduação em Crítica Cultural da UNEB, Campus II, Alagoinhas. Endereço eletrônico: ricofrei@gmail.com. 